\title{
Novel Structures Observed in the Brain of a Patient with Amyotrophic Lateral Sclerosis
}

\section{Likun Wang ${ }^{1}$, Xinmei Luo ${ }^{2}$, and Guofeng $\mathrm{Wu}^{1 *}$ \\ ${ }^{1}$ Department of Neurology, Affiliated Hospital of Guizhou Medical University, China}

${ }^{2}$ Department of Geriatric medicine, Affiliated Hospital of Guizhou Medical University, China

Submission:July 18, 2017; Published: September 22, 2017

*Corresponding author: Guofeng Wu, Department of Neurology, Affiliated Hospital of Guizhou Medical University, No. 28, Guiyijie Road, Liuguangmen, Guiyang City, Guizhou Province, PRC, Postal code 550004, China, Tel: +86-1380-9431-723; Fax: +86-0851-6850-654; Email: wuguofeng3013@sina.com

\section{Background}

Amyotrophic lateral sclerosis (ALS) is the most common and most severe form of the motor neuron disease [1]. Patients with ALS progressively lose their ability to control voluntary movements and occasionally enter the totally locked-in state, in which they cannot move any part of their bodies including the eyes [2]. Electron microscope examination performed

in ALS mice showed disorganized mitochondrial cristae and degenerating mitochondria in endothelial cells, astrocytes and motor neurons and extensive extracellular edema [3]. However, the brain ultrastructure of patients with ALS have poorly been reported [4,5]. Here, we reported a case of ALS patient with novel structures in his brain.

\section{Clinical Report}
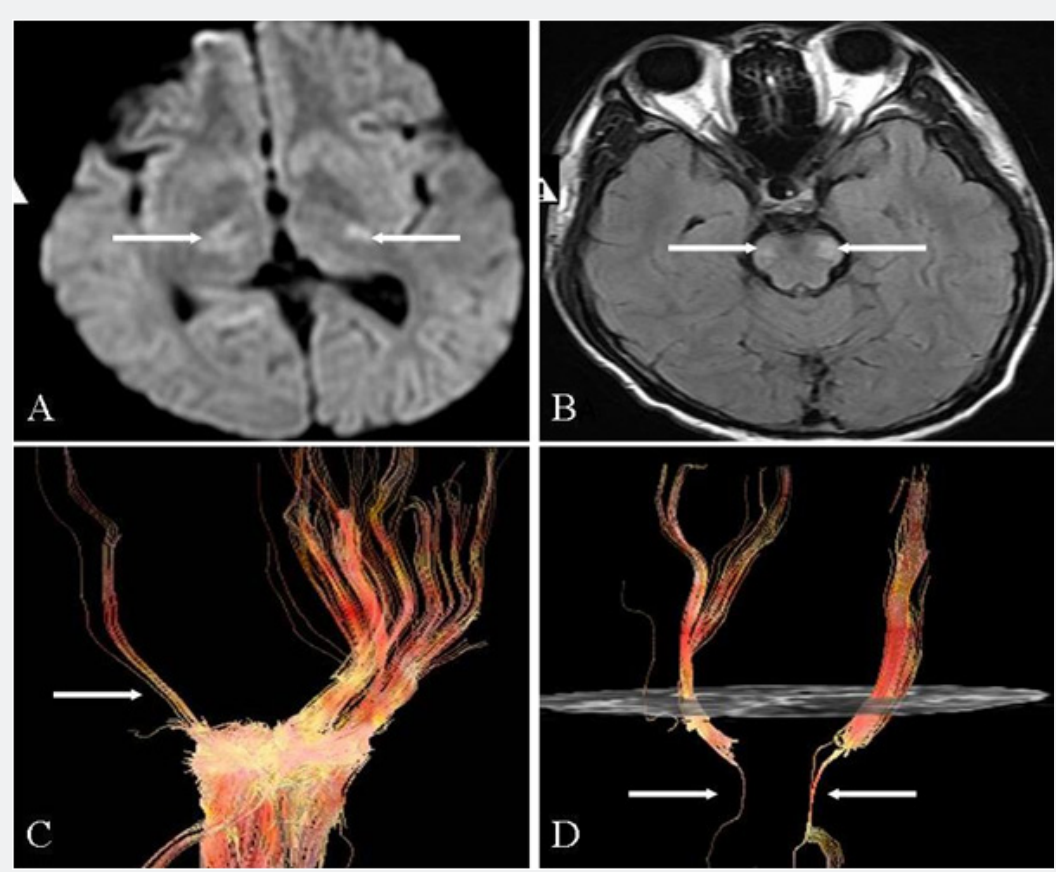

Figure 1: Brain MRI and diffusion tensor imaging of the patient.

High signals were observed in brainstem and bilateral internal capsules, the thalamus especially the right one was involved (A and B). Diffusion tensor imaging revealed that the neruofibers decreased or disrupted significantly in the internal capsules as well as in the brainstem (C and D). 


\section{Open Access Journal of Neurology \& Neurosurgery}

A 23 years old man progressively developed four limbs weakness and atrophy for 2 years, dysarthria and choking for 1 year and breathing difficult, urinary difficulty for 1 month. It seems response to steriods for a while. The symptoms progress after stop taking steriods. Neurological examination found an increased muscle tone and decreased muscle strength of the four limbs, hyperreflexia and bilateral babinskin sign positive, muscle atrophy of lower limbs. A magnetic resonance imaging showed diffused lesion in the brain. The basal part of the pontine, bilateral peduncles, the ventral midbrain, especially the bilateral posterior limbs of the internal capsule and the thalamus were involved (Figure1A \& 1B). DTI showed that the fibers in the internal capsule and the brainstem are decreased significantly or interrupted completely (Figure1C \& 1D). EMG showed diffused neurogenic lesion of four limbs, the sternocleidomastoid muscle was involved. Abnormalities were not found in the blood routine, kidney and liver function, blood electrolyte, serum enzymology. The related gene for SOD1 mutation inspection was normal. A biopsy of the abnormal brain tissues were performed based on the abnormal signals on magnetic resonance images, and the informed consent was obtained from his legally authorized representative. The results displayed abnormal structures in the cytoplasma of the neuron Under light microscope, significant edema and large amount of edematous vacuoles were observed in the brain tissues. The neurons were deformed and the Niss body disappeared. The nuclear structures of the neurons were ambiguous. Vacuoles as well as infiltrated neurogliocytes were observed in the cytoplasm (Figure 2A \& 2B). Electronic microscope displayed abnormal structures in the cytoplasma of the neurons (Figure 2C \& 2D). The metachromatic substances deposited in the cyto-plasma were characterized by electronic dense granules. Disorganized and degenerating mitochondria were observed in astrocytes and neurons.. Three years after onset of the symptoms, the young man developed completely paralyzed, bedridden, and pseudobulbar paralysis. Finally, he died of severe pulmonary infection.

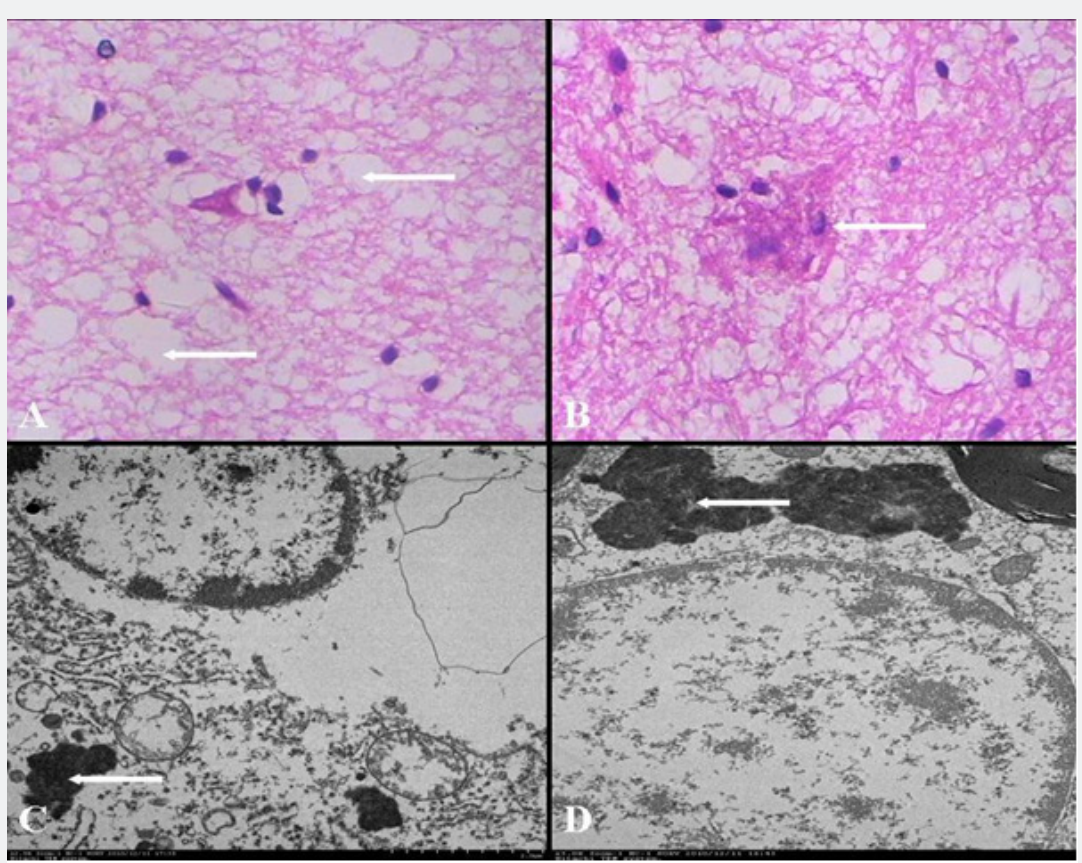

Figure 2: Pathological findings.

Extensive extra-cellular edema was observed in the internal capsule and the thalamus (A). Neuron necrosis and degenerations were also observed in the brain. The neurons were deformed and the Niss body disappeared. The nuclear structures of the neurons were ambiguous. Vacuoles as well as infiltrated neurogliocytes were observed in the cytoplasma (B). The electronic microscope demonstrated that the metachromatic substances deposited in the cyto-plasma were characterized by electronic dense granules (C and D). Disorganized and degenerating mitochondria were observed in astrocytes and neurons.

\section{Discussion}

This is an interesting case. The man is quite young, so one needs to think about a hereditary disorder, like an SOD1 mutation. If there are other symptoms one needs to think about a number of syndromes, including tau mutations in the presence of dementia, etc. However, the man did not show any symptoms but decreased motor function. SOD1 mutation gene inspection was normal. From the clinical and imaging perspective5, people could make the diagnosis of the ALS. In the ultrastructural studies, there are membrane bound and not membrane bound accumulation of fibrillary material, as well as spheroid bodies. Mitochondria are swollen, sometimes with vacuoles inside. This demonstrates that the cells are undergoing a process of degeneration. Such changes are seen in different cell types in SOD1 mutations, including in muscle in transgenic animals. At electron microscopy, some features may let us think about metachromatic leukodystrophy, especially the stacked 
myelin aggregates. In metachromatic leudodystrophy people would expect lipid filled macrophages, granular myelin debris and reactive astrocytes. As far as someone can judge from the selection of MRI picture, the signal alteration is really along the cortico-spinal tract, not within the white matter, as some people would expect in metachromoatic leukodystrophy.

\section{References}

1. Akhvlediani T, Kvirkvelia N, Shakarishvili R, Tsertsvadze T (2009) Alslike syndrome in the patient with chronic hepatitis C. Georgian medical news (172-173): 70-72.
2. Fuchino $Y$, Nagao M, Katura $T$ (2008) High cognitive function of an ALS patient in the totally locked-in state. Neuroscience letters 435(2): 8589.

3. Garbuzova-Davis S, Haller E, Saporta S, Kolomey I, Nicosia SV, et al. (2007) Ultrastructure of blood-brain barrier and blood-spinal cord barrier in SOD1 mice modeling ALS. Brain research 1157: 126-137.

4. Kusaka H, Imai T (1993) Pathology of motor neurons in amyotrophic lateral sclerosis with dementia. Clinical neuropathology 12(3): 164168.

5. Blumen SC, Inzelberg R, Nisipeanu P, Carasso RL, Oved D, et al. (2010) Aggressive familial ALS with unusual brain MRI and a SOD1 gene mutation. Amyotroph Lateral Scler 11(1-2): 228-231.

This work is licensed under Creative Commons Attribution 4.0 Licens DOI: 10.19080/OAJNN 2017 6.555681
Your next submission with Juniper Publishers will reach you the below assets

- Quality Editorial service

- Swift Peer Review

- Reprints availability

- E-prints Service

- Manuscript Podcast for convenient understanding

- Global attainment for your research

- Manuscript accessibility in different formats ( Pdf, E-pub, Full Text, Audio)

- Unceasing customer service

Track the below URL for one-step submission https://juniperpublishers.com/online-submission.php 